\title{
Actinobacillus succinogenes sp. nov., a novel succinic-acid-producing strain from the bovine rumen
}

\author{
Michael V. Guettler, ${ }^{1}$ Denise Rumler ${ }^{1}$ and Mahendra K. Jain ${ }^{1,2}$ \\ Author for correspondence: Mahendra K. Jain (MBI International). Tel: +1 5173364626. \\ Fax: + 1517337 2122. e-mail: jain@mbi.org
}

1 MBI International, 3900 Collins Road, PO Box 27609, Lansing, MI 48909, USA

2 Department of Animal Science, Michigan State University, East Lansing, MI 48824, USA

\begin{abstract}
Strain $130 Z^{\top}$ was isolated from the bovine rumen. It is a facultatively anaerobic, pleomorphic, Gram-negative rod. It exhibits a 'Morse code' form of morphology, which is characteristic of the genus Actinobacillus. Strain ${ }^{130 z^{\top}}$ is a capnophilic, osmotolerant succinogen that utilizes a broad range of sugars. It accumulates high concentrations of succinic acid $\left(>70 \mathrm{~g} \mathrm{I}^{-1}\right)$. Strain $130 \mathrm{Z}^{\top}$ is positive for catalase, oxidase, alkaline phosphatase and $\beta$-galactosidase, but does not produce indole or urease. Acid but no gas is produced from D-glucose and D-fructose. $16 S$ rRNA sequence analysis places strain $130 Z^{\top}$ within the family Pasteurellaceae; the most closely related members of the family Pasteurellaceae have 165 rRNA similarities of $95 \cdot 5 \%$ or less with strain $130 Z^{\top}$. Strain $130 Z^{\top}$ was compared with Actinobacillus lignieresii and the related Bisgaard Taxa 6 and 10. Based upon morphological and biochemical properties, strain $130 \mathrm{Z}^{\top}$ is most similar to members of the genus Actinobacillus within the family Pasteurellaceae. It is proposed that strain $130 Z^{\top}$ be classified as a new species, Actinobacillus succinogenes. The type strain of Actinobacillus succinogenes Sp. nov. is ATCC 55618'.
\end{abstract}

Keywords: Actinobacillus succinogenes sp. nov., succinic acid, rumen, Pasteurellaceae

\section{INTRODUCTION}

The family Pasteurellaceae is formally composed of three genera, Pasteurella, Haemophilus and Actinobacillus. There are more than 80 described species and taxa that are either members or potential members of this family (Dewhirst et al., 1993). There are also many strains with morphological, cultural and biochemical characteristics consistent with this family that have not been fully described (Mannheim, 1984). None of these bacteria are known to be free living but have been obtained from mammalian, avian and reptilian sources. Some species cause disease but most species are recognized as commensals in the respiratory, alimentary and reproductive tracts of animals. Very little has been published regarding possible symbiotic activities

Abbreviations: ALA, $\delta$-aminolaevulinic acid; CSL, corn steep liquor; FAMEs, fatty acid methyl esters; TMP, thiamin monophosphate.

The GenBank accession number for the 165 rRNA sequence of strain $130 Z^{\top}$ is AF024525. performed by these many species that live in close association with animals.

Bacteria that degrade the tannin/protein complex were recently described; they may be key to the digestion of tannin-bound protein in the alimentary tract of the koala (Osawa et al., 1995). Lonepinella koalarum was placed within the family Pasteurellaceae based on analysis of its $16 \mathrm{~S}$ rRNA sequence. This species colonized the caecum of koalas which have a diet with a high tannin content and it made up $60 \%$ of the faecal flora.

Thirty-eight years ago, Phillips (1961) used an antibiotic-containing medium to isolate actinobacillus-like micro-organisms from ruminal contents and proposed that there were 'rumen actinobacilli' with a fermentative role in microbial digestion. Phillips (1961) characterized Actinobacillus lignieresii and attempted to identify a symbiotic form of this species with an enhanced fermentative activity. In the rumen, bacteria convert plant carbohydrates to fatty acids and, to a very large extent, succinic acid (Stewart \& Bryant, 
1988). The succinic acid is decarboxylated to propionic acid, which is utilized in the gluconeogenic pathway of the ruminant host, and the gas mixture in the rumen contains $65 \%$ (v/v) $\mathrm{CO}_{2}$ (Yokoyama \& Johnson, 1988).

Twenty-nine bovine rumen strains obtained by Phillips (1961) were re-examined and only three could be identified as $A$. lignieresii (Bisgaard et al., 1986). While most of the rumen strains had phenotypic characters compatible with Pasteurellaceae, they could not be identified as accepted species within the family. Since the 1960 s, it has become increasingly apparent that classification of new strains as members of the Pasteurellaceae is difficult even with extended phenotypic characterization. Increased knowledge regarding the family Pasteurellaceae has revealed a phylogenetic complexity that may require more than seven genera to accommodate the major phenotypic divisions. Differentiating new species within the family Pasteurellaceae has become dependent on sequencing the genes encoding 16S rRNA (Dewhirst et al., 1993; Foster et al., 1996; Osawa et al., 1995).

Recent physiological and biochemical studies have indicated that strain $130 \mathrm{Z}^{\mathrm{T}}$ produces succinate-pathway enzymes in much higher amounts than other succinic-acid-producing bacteria (Van der Werf et al., 1997). In this paper, a description of this novel succinic-acid-producing strain isolated from the bovine rumen is presented, including its cultural and biochemical characteristics and its phylogenetic position within the family Pasteurellaceae based upon complete 16S rRNA sequence information.

\section{METHODS}

Source of strains. Strain $130 \mathrm{Z}^{\mathrm{T}}$ (ATCC 55618 ${ }^{\mathrm{T}}$ ) was isolated at MBI International from bovine ruminal contents. $A$. lignieresii (ATCC 49236 ${ }^{\mathrm{T}}$ ) and Staphylococcus aureus (ATCC 6538P) were obtained from the American Type Culture Collection (ATCC). Reference strains of Bisgaard Taxon 6 (CCUG 15568) and Bisgaard Taxon 10 (CCUG 15572) were obtained from the Culture Collection at the University of Göteborg (CCUG). The Bisgaard Taxa 6 and 10 are related to strain $130 Z^{\mathrm{T}}$ and $A$. lignieresii is a nonfastidious organism that is outwardly similar to strain $130 \mathrm{Z}^{\mathrm{T}}$ and a normal inhabitant of the bovine rumen. All three strains were tested simultaneously with strain $130 \mathrm{Z}^{\mathrm{T}}$ for cultural and biochemical properties. $S$. aureus was used to test for growth stimulation from cross feeding.

Enrichment and isolation. Ruminal contents were collected from surgically cannulated cattle and used as an inoculum for an enrichment medium containing the ionophoric antibiotic lasalocid (Sigma). Two subcultures were made after $18 \mathrm{~h}$ incubation at $37^{\circ} \mathrm{C} ; 10 \%$ inocula were used. The final enrichment culture was diluted $\left(10^{-6}\right)$ in PBS $(0 \cdot 145 \mathrm{M} \mathrm{NaCl}$, $0.01 \mathrm{M}$ sodium phosphate) and $0.1 \mathrm{ml}$ was spread onto agar plates. Plates were incubated in an Oxoid anaerobic jar with a $\mathrm{CO}_{2}$ atmosphere. After 24-48 h, single-well-isolated colonies were picked with a 22 gauge needle and washed into vials of enrichment medium without lasalocid or fumarate (Macy et al., 1972; Miller \& Wolin, 1974). Primary isolates were grown for $24-36 \mathrm{~h}$ and samples were analysed by HPLC and screened for succinic acid production. The enrichment medium contained $\left(1^{-1}\right): 20 \mathrm{~g}$ corn steep liquor (CSL) containing approximately $50 \%$ dry matter (Corn Products), $15.0 \mathrm{~g}$ glucose, $15.0 \mathrm{~g}$ sodium fumarate, $15.0 \mathrm{~g}$

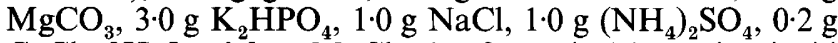
$\mathrm{CaCl}_{2} \cdot 2 \mathrm{H}_{2} \mathrm{O}, 0 \cdot 2 \mathrm{~g} \mathrm{MgCl} .6 \mathrm{H}_{2} \mathrm{O}$ and $16 \mathrm{mg}$ lasalocid (Sigma). Plates used for isolation were made similarly but contained $\left(1^{-1}\right): 10 \cdot 0 \mathrm{~g}$ Bacto peptone and $5 \cdot 0 \mathrm{~g}$ Bacto yeast extract substituted for the CSL, $15.0 \mathrm{~g} \mathrm{MgCO}_{3}$ and $1.8 \mathrm{~g}$ Bacto agar (Difco). The plates used for isolation also contained the following additions and vitamins $\left(1^{-1}\right): 1.4 \mathrm{~g}$ sodium acetate, $1.0 \mathrm{~g}$ xylose, $0.2 \mathrm{ml}$ methyl butyric acid, $0.2 \mathrm{ml}$ valeric acid, $0.2 \mathrm{ml}$ isobutyric acid, $0.2 \mathrm{ml}$ isovaleric acid, $500 \mu \mathrm{g}$ haemin, $100 \mu \mathrm{g} \mathrm{B}_{6}, 50 \mu \mathrm{g}$ lipoic acid, $20 \mu \mathrm{g}$ thiamin, $20 \mu \mathrm{g}$ riboflavin, $20 \mu \mathrm{g}$ niacin, $20 \mu \mathrm{g}$ pantothenate, $20 \mu \mathrm{g} p$-aminobenzoate, $10 \mu \mathrm{g}$ 1,4-naphthoquinone, $1 \mu \mathrm{g}$ $\mathrm{B}_{12}, 1 \mu \mathrm{g}$ biotin and $1 \mu \mathrm{g}$ folic acid. The enrichment and isolation media were prepared and sterilized anaerobically (Holdeman et al., 1977; Zeikus et al., 1980).

Analysis. The organic acid fermentation products were determined by HPLC (Guerrant et al., 1982). Components were analysed chromatographically by elution with $0.006 \mathrm{M}$ $\mathrm{H}_{2} \mathrm{SO}_{4}$ from a cation exchange resin in the hydrogen form. A Waters model $600 \mathrm{HPLC}$ system with a Bio-Rad HPX-87H column and a Waters model 410 Refractive Index detector were used in this analysis. Residual glucose was determined by the same method.

Morphological and physiological characterization. To test the effects of $\mathrm{CO}_{2}$ and $\mathrm{N}_{2}$ atmospheres on growth, Oxoid jars were flushed and evacuated three times before filling with $\mathrm{CO}_{2}$ or $\mathrm{N}_{2}$. A mixture of approximately $40 \%(\mathrm{v} / \mathrm{v}) \mathrm{CO}_{2}$ was obtained by adding $\mathrm{CO}_{2}$ to $69 \mathrm{kPa}$ into an air- or $\mathrm{N}_{2}$ containing jar; an Oxoid jar filled with $\mathrm{CO}_{2}$ and topped up with $\mathrm{N}_{2}$ to $69 \mathrm{kPa}$ contained approximately $60 \%$ (v/v) $\mathrm{CO}_{2}$ by calculation. The $5 \%(\mathrm{v} / \mathrm{v}) \mathrm{CO}_{2}$ and $\mathrm{N}_{2}$ mixture was obtained commercially.

The test for fumarate reduction was done as previously described (Hollander et al., 1981). A sterile sodium fumarate stock solution was added to give a $50 \mathrm{mM}$ fumarate concentration in pressure tubes containing $10 \mathrm{ml}$ yeast extract medium and an $\mathrm{N}_{2} / \mathrm{CO}_{2}$ atmosphere. The medium contained $\left(1^{-1}\right): 5 \cdot 0 \mathrm{~g}$ yeast extract, $0 \cdot 19 \mathrm{~g} \mathrm{NaH_{2 }} \mathrm{PO}_{4} . \mathrm{H}_{2} \mathrm{O}$ and $0.5 \mathrm{~g} \mathrm{Na}_{2} \mathrm{HPO}_{4}$. A $0.1 \%$ inoculum was used and incubation was stationary at $37^{\circ} \mathrm{C}$. Turbidity was read with a Spectronic 20 spectrophotometer (Milton Roy) at $600 \mathrm{~nm}$.

Biochemical characterization. For the biochemical testing, all strains were grown for $20-24 \mathrm{~h}$ at $37^{\circ} \mathrm{C}$ on TSB agar plates made with Trypticase Soy Broth (BBL) containing $1.8 \%$ (w/v) Bacto agar (Difco). For biochemical testing, $A$. lignieresii was grown aerobically, and Bisgaard Taxon 6 and Bisgaard Taxon 10 strains were grown with $40 \%(\mathrm{v} / \mathrm{v}) \mathrm{CO}_{2}$. Cells of strain $130 Z^{\mathrm{T}}$ grown aerobically and with 40 and $100 \%$ (v/v) $\mathrm{CO}_{2}$ were tested separately for comparison. The isolates were biochemically characterized using the API $50 \mathrm{CH}$ system with CHB medium, the API 20E system, the API OF medium (bioMérieux), and the RapID ANA II system (Innovative Diagnostic Systems) according to the manufacturers' instructions. The API 50CH, API $20 \mathrm{E}$ and the RapID ANA II systems were inoculated with cell suspensions with an $\mathrm{OD}_{550 \mathrm{~nm}}$ of approximately $0 \cdot 75$, and the API ZYM system was inoculated with cell suspensions of approximately $1.5 \mathrm{OD}_{550 \mathrm{~nm}}$. Each set of tests was repeated at least twice. The oxidase test was performed using a drop of a fresh preparation of $0.5 \% \quad N, N, N^{\prime}, N^{\prime}$-tetramethyl-p- 
Table 1. Oligonucleotide primers used for PCR amplification and sequencing of 165 rDNA

\begin{tabular}{|c|c|c|c|c|c|}
\hline Primer & Identification & Type & Sequence $\left(5^{\prime}-3^{\prime}\right)^{*}$ & Position $\dagger$ & Orientation \\
\hline 1 & $\mathrm{C} 70$ & PCR & AGAGTTTGATYCTGGCT & $8-24$ & Forward \\
\hline 2 & B37 & PCR & TACGGYTACCTTGTTACGACT & $1493-1513$ & Reverse \\
\hline 3 & B34 & Sequencing & ACTGCTGCCTCCCGT & $344-358$ & Reverse \\
\hline 4 & B35 & Sequencing & GTRTTACCGCGGCTGCTG & $519-536$ & Reverse \\
\hline 5 & B36 & Sequencing & CTACCAGGGTATCTAATC & $786-804$ & Reverse \\
\hline 6 & $\mathrm{C} 01$ & Sequencing & GGTTGCGCTCGTTGCGGG & $1096-1113$ & Reverse \\
\hline 7 & $\mathrm{C} 31$ & Sequencing & GGAATCGCTAGTAATCG & $1337-1353$ & Forward \\
\hline 8 & $\mathrm{X} 91$ & Sequencing & CCCGGGAACGTATTCACCG & $1369-1387$ & Reverse \\
\hline
\end{tabular}

* Standard International Union of Biochemistry codes are used for bases.

$\uparrow$ Based upon E. coli numbering.

Table 2. Accession numbers of strains included in the similarity matrix and levels of $16 \mathrm{~S}$ rRNA similarity between Actinobacillus succinogenes sp. nov. and other representatives of the family Pasteurellaceae

\begin{tabular}{|c|c|c|c|}
\hline Strain & $\begin{array}{c}\text { Culture collection } \\
\text { no. }\end{array}$ & GenBank no. & $\begin{array}{c}\text { Sequence similarity to } \\
\text { Actinobacillus } \\
\text { succinogenes }(\%)\end{array}$ \\
\hline Actinobacillus succinogenes & ATCC $55618^{\mathrm{T}}$ & AF024525 & 100 \\
\hline Actinobacillus actinomycetemcomitans & ATCC $33384^{\mathrm{T}}$ & M75039 & $92 \cdot 1$ \\
\hline Actinobacillus equuli & NCTC $8529^{\mathrm{T}}$ & M75072 & $92 \cdot 8$ \\
\hline Actinobacillus hominis & CCUG $19800^{\mathrm{T}}$ & L06076 & $92 \cdot 7$ \\
\hline Actinobacillus lignieresii & ATCC $49236^{\mathrm{T}}$ & M75068 & $93 \cdot 8$ \\
\hline Actinobacillus muris & CCUG 16938 & AF024526 & $92 \cdot 9$ \\
\hline Actinobacillus seminis & ATCC $15768^{\mathrm{T}}$ & M75047 & 93.6 \\
\hline Actinobacillus suis & ATCC 15557 & M75071 & $92 \cdot 6$ \\
\hline Actinobacillus ureae & Henriksen $3520 / 59^{\mathrm{T}}$ & M75075 & $92 \cdot 8$ \\
\hline Actinobacillus/Pasteurella-like & CCUG 28030 & AF024527 & $93 \cdot 6$ \\
\hline Bisgaard Taxon 10 & CCUG 15572 & AF024528 & $95 \cdot 4$ \\
\hline Bisgaard Taxon 17 & CCUG 17206 & AF024529 & $92 \cdot 8$ \\
\hline Bisgaard Taxon 6 & CCUG 15568 & L06081 & $95 \cdot 5$ \\
\hline Bisgaard Taxon 9 & CCUG 24862 & L06084 & $92 \cdot 7$ \\
\hline Haemophilus aegyptius & NCTC $8502^{\mathrm{T}}$ & M75044 & $93 \cdot 2$ \\
\hline Haemophilus aphrophilus & ATCC $33389^{\mathrm{T}}$ & M75041 & $93 \cdot 4$ \\
\hline Haemophilus aphrophilus & ATCC 7901 & M75040 & $93 \cdot 3$ \\
\hline Haemophilus haemolyticus & NCTC $10659^{\mathrm{T}}$ & M75045 & $94 \cdot 1$ \\
\hline Haemophilus influenzae & ATCC 33391 & M35019 & $93 \cdot 2$ \\
\hline Haemophilus influenzaemurium & NCTC 11146 & AF024530 & $91 \cdot 7$ \\
\hline Haemophilus paraphrophilus & ATCC $29241^{\mathrm{T}}$ & M75042 & $93 \cdot 4$ \\
\hline Haemophilus segnis & ATCC $33393^{\mathrm{T}}$ & M75043 & $94 \cdot 1$ \\
\hline 'Haemophilus somпus' & OVCG 43826 & M75046 & $93 \cdot 6$ \\
\hline Pasteurella aerogenes & ATCC $27883^{\mathrm{T}}$ & M75048 & 93.9 \\
\hline Pasteurella haemolytica-like & CCUG 28028 & AF024531 & $92 \cdot 1$ \\
\hline Pasteurella mairii & CCUG 27189 & L06089 & $92 \cdot 2$ \\
\hline Pasteurella pneumotropica & NCTC $8141^{\mathrm{T}}$ & M75083 & $93 \cdot 2$ \\
\hline
\end{tabular}

phenylenediamine dihydrochloride (Sigma) on filter paper. The slide catalase test was performed with $1.5 \%(\mathrm{w} / \mathrm{v}) \mathrm{H}_{2} \mathrm{O}_{2}$ solution to confirm the API 20E catalase determination. The cells were tested for oxidase and catalase as described previously (MacFaddin, 1980). The $\delta$-aminolaevulinic acid
(ALA; Sigma) test was done as described previously to test for porphyrin synthesis (Kilian \& Biberstein, 1984). Growth stimulation by thiamin monophosphate (TMP) and by cross feeding with $S$. aureus was tested on TSB agar plates as previously described (Stephens et al., 1983). 
Cellular fatty acid analysis. The cellular fatty acid compositions of strain 130Z, A. lignieresii and the Bisgaard Taxa were determined with cells grown aerobically for $48 \mathrm{~h}$ on TSB agar at $28^{\circ} \mathrm{C}$. Fatty acid methyl esters (FAMEs) were synthesized and analysed with the MIDI Microbial Identification System as described previously (Sasser, 1990). Briefly, whole cells were treated with $\mathrm{NaOH}$ in aqueous methanol at $100^{\circ} \mathrm{C}$. The whole-cell methanolysis and saponification were followed with methylation using $\mathrm{HCl}$ in aqueous methanol; FAMEs were extracted with hexan$\mathrm{e} /$ methyl-tert-butyl-ether $(1: 1, \mathrm{v} / \mathrm{v})$ and washed with dilute $\mathrm{NaOH}$. Chromatographic analysis was made with a HewlettPackard gas model 5890 Series II, with an HP 7673 automatic sampler and flame-ionization detector. Separation was done with an HP-1 capillary column $(25 \mathrm{~m} \times 0.2 \mathrm{~mm} \times 0.33 \mu \mathrm{m})$ with $\mathrm{H}_{2}$ as the carrier gas. FAME identification and analysis was done using the Microbial Identification System software for anaerobic and aerobic bacteria.

16S rRNA sequence analysis. The 16S rRNA sequence determination was done on a 'fee for service' basis by Floyd E. Dewhirst (Forsyth Dental Center, Boston, MA, USA) using previously described methods (Mendes et al., 1996). Briefly, DNA was isolated from cells of strain $130 Z^{\mathrm{T}}$ by a proteinase $\mathrm{K}$ method. The $16 \mathrm{~S}$ rRNA genes were amplified using primers 1 and 2 (see Table 1). The amplicon was purified by the PEG 800 purification method of Kusukawa et al. (1990). The amplicon was cycle-sequenced as previously described using the primers in Table 1 (Mendes et al., 1996). The 16S rRNA sequence was analysed using programs written in Microsoft QuickBasic (Paster \& Dewhirst, 1988). The sequence database contains over 1000 sequences determined at the Forsyth Dental Center, including over 150 sequences for strains in the family Pasteurellaceae and 500 sequences obtained from GenBank and the Ribosomal Database Project (Maidak et al., 1997). Similarity matrices were constructed from the aligned sequences using only those sequence positions for which $90 \%$ of the strains had data. The similarity matrices were corrected for multiple base changes at single positions by the method of Jukes \& Cantor (1969). A phylogenetic tree was constructed using the neighbour-joining method of Saitou \& Nei (1987) and Studier \& Keppler (1988).

GenBank accession numbers. The GenBank and culture collection accession numbers for the strains examined in this report are given in Table 2 .

Determination of DNA $\mathbf{G}+\mathbf{C}$ content. The DNA $\mathrm{G}+\mathrm{C}$ determination was performed by William B. Whitman (University of Georgia, Athens, GA, USA). The G+C content of DNA obtained from strain $130 \mathrm{Z}^{\mathrm{T}}$ was determined by HPLC (Mesbah et al., 1989).

\section{RESULTS AND DISCUSSION}

\section{Enrichment, isolation and succinic acid production}

The medium used for enrichment and isolation was an organic acid production medium that contained glucose and CSL as its primary constituents. Many of the isolated strains were obligate anaerobes that produced primarily succinic acid and shared other similarities with well-known rumen species.

Strain $130 Z^{T}$ was part of a second group of isolates that were facultatively anaerobic. Strain $130 Z^{T}$ pro- duced more than $30 \mathrm{~g}$ succinic acid $\mathrm{l}^{-1}$ in the enrichment vials containing $\mathrm{CSL}$ and $\mathrm{MgCO}_{3}$. The succinic acid was produced along with acetic acid in high ratios (e.g. 5:1-8:1). Formic acid was also produced along with small amounts of pyruvic acid, oxaloacetic acid and ethanol. Growth and acid production were stimulated by additions of yeast extract to the CSL enrichment medium.

For the purpose of comparison, strain $130 Z^{\mathrm{T}}$ and $A$. lignieresii were grown in TSB medium in a $5 \%(\mathrm{v} / \mathrm{v})$ $\mathrm{CO}_{2}$ atmosphere. The two species produced similar acid profiles in this poorly buffered medium containing less than $2 \mathrm{~g}$ glucose $1^{-1}$. However, strain $130 \mathrm{Z}^{\mathrm{T}}$ produced approximately three times as much succinic acid (data not shown). An increased $\mathrm{CO}_{2}$ concentration stimulated growth and succinic acid production by strain $130 \mathrm{Z}$. A lignieresii did not grow in any media that contained insoluble $\mathrm{MgCO}_{3}$, or with high concentrations of $\mathrm{CO}_{2}$ in the gas phase.

\section{General and growth characteristics}

Strain $130 Z^{T}$ is a non-motile, non-spore-forming, fermentative, facultatively anaerobic, pleomorphic Gram-negative rod or coccobacillus. It is a nonfastidious organism that grows rapidly on blood-free media. It grew on simple chemo-organotrophic media such as $0.4 \%$ yeast extract with glucose and phosphate. It was positive for the ALA test and did not require NAD or other special growth factors. Growth of strain $130 \mathrm{Z}^{\mathrm{T}}$ was not stimulated by TMP or cross-fed by $S$. aureus. Strain $130 \mathrm{Z}^{\mathrm{T}}$ was mesophilic and grew well at $37-39^{\circ} \mathrm{C}$, whereas no growth was observed on TSB agar plates at 20 or $45^{\circ} \mathrm{C}$. The strain did not grow in TSB containing $4.5 \%(\mathrm{w} / \mathrm{v}) \mathrm{NaCl}$.

Strain $130 Z^{T}$ grew aerobically and was capnophilic since although it grew satisfactorily in air, its growth was enhanced in an atmosphere that contained an increased $\mathrm{CO}_{2}$ concentration. After $24 \mathrm{~h}$ incubation at $37^{\circ} \mathrm{C}$ in $\mathrm{CO}_{2}$, colonies of strain $130 \mathrm{Z}^{\mathrm{T}}$ on TSB agar were circular, entire, grey, translucent and $1-1.5 \mathrm{~mm}$ in diameter. There was slightly more growth at $5-40 \%$ (v/v) $\mathrm{CO}_{2}$ and isolated colonies were slightly larger than those produced at $60-100 \%(\mathrm{v} / \mathrm{v}) \mathrm{CO}_{2}$. Growth produced at 5-100\% (v/v) $\mathrm{CO}_{2}$ was smooth and did not adhere to the plate. Growth produced in the air adhered to the agar surface, while growth produced without $\mathrm{CO}_{2}\left(100 \% \mathrm{~N}_{2}\right)$ was sticky but non-adherent. Growth without $\mathrm{CO}_{2}$ was poor even with several days incubation.

Cells grown with $100 \% \quad \mathrm{CO}_{2}$ occurred singly $(0.8 \times 1 \mu \mathrm{m})$, in pairs and in short chains. Occasional filamentous cells $(0 \cdot 8-1 \cdot 2 \times 10-85 \mu \mathrm{m})$ were seen in most cultures. Cells produced in an atmosphere of $\mathrm{CO}_{2}$ $(\geqslant 40 \%, v / v)$ were the most uniform and the least pleomorphic. Cells produced at $5 \%(\mathrm{v} / \mathrm{v}) \mathrm{CO}_{2}$ were swollen and pleomorphic. Cells produced without $\mathrm{CO}_{2}$ were more swollen, pleomorphic and appeared to be in a poor condition. 

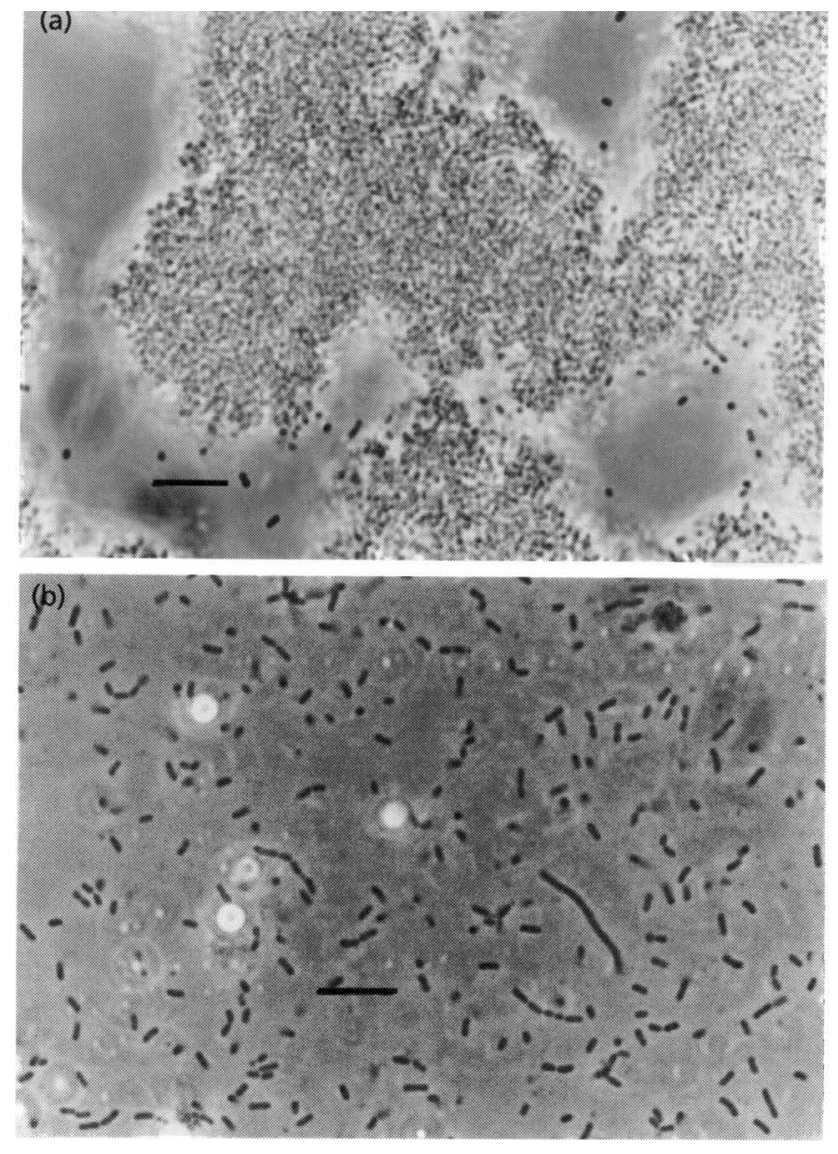

Fig. 1. Phase-contrast micrographs of strain $130 Z^{\top}$. (a) Cells grown aerobically on TSB agar. (b) Uniform and moniliform chains of cells grown in yeast extract/CSL broth with $\mathrm{MgCO}_{3}$ and $100 \% \mathrm{CO}_{2}$. Bar, $10 \mu \mathrm{m}$.

Aerobically grown cultures produced large sheets of cells apparently cemented together by a matrix of extracellular material (Fig. 1a). The presence of large sheets of cells in air-grown cultures corresponded with the adherence of colonies to the agar surface. Small aggregates of cells occurred in all TSB cultures. Strain $130 \mathrm{Z}^{\mathrm{T}}$ produced chains of coccoidal cells in rapidly growing broth cultures. 'Morse code' forms that have bacillary and coccoidal elements interspersed with each other were also easily found in broth cultures (Fig. 1b).

Strain $130 \mathrm{Z}^{\mathrm{T}}$ grew rapidly and extensively, utilizing Larabinose, cellobiose, fructose, galactose, glucose, lactose, maltose, mannitol, mannose, sucrose, D-xylose or salicin in media made with yeast extract and CSL.

\section{Biochemical characterization}

Strain $130 \mathrm{Z}^{\mathrm{T}}$ was positive for catalase, oxidase, $\beta$ galactosidase (ONPG) and nitrate reduction. It was negative for arginine dihydrolase, lysine decarboxylase, ornithine decarboxylase, citrate utilization, $\mathrm{H}_{2} \mathrm{~S}$, urease, tryptophan deaminase, tryptophanase (indole),
Table 3. Comparison of phenotypic characteristics of the bovine rumen isolate, strain $130 Z^{\top}$, with the type strains of the genus Actinobacillus and the related Bisgaard Taxa 6 and 10

All strains produced a negative reaction for ornithine decarboylase, lysine decarboxylase, citrate utilization, gelatin hydrolysis, $\mathrm{H}_{2} \mathrm{~S}$, indole, tryptophan deaminase, acid from adonitol, amidon, L-arabitol dulcitol, erythritol, D-fucose, glycogen, inositol, inulin, 2-ketogluconate, D-lyxose melezitose, methyl $\alpha$-D-mannoside, methyl $\alpha$-D-glucoside, methyl $\beta$-xyloside, D-tagatose, D-turanose, L-sorbose, xylitol and $\mathrm{L}$-xylose. All strains produced a positive test with $\beta$ galactosidase (ONPG), nitrate reduction, acid from D-ribose, galactose, D-glucose, D-fructose, D-mannose, maltose, raffinose and sucrose. $1, A$. succinogenes sp. nov. ATCC $55618^{\mathrm{T}} ; 2$, A. lignieresii ATCC 49236; 3, Bisgaard Taxon 6 CCUG 15568; and 4, Bisgaard Taxon 10 CCUG 15572.

\begin{tabular}{|lcccc|}
\hline Test & $\mathbf{1}$ & $\mathbf{2}$ & $\mathbf{3}$ & $\mathbf{4}$ \\
\hline Catalase & + & - & - & - \\
Oxidase (TMPD) $\dagger$ & + & + & - & - \\
Urease & - & + & + & + \\
Acetoin (Voges-Proskauer) & - & + & + & + \\
D-Glucose (gas) & - & - & + & + \\
O/F* & F & F & F & F \\
Acid from: & & & & \\
Glycerol & - & + & + & + \\
D-Arabinose & - & - & + & + \\
L-Arabinose & + & - & + & + \\
D-Xylose & + & + & + & - \\
L-Rhamnose & - & - & - & + \\
D-Mannitol & + & + & - & + \\
D-Sorbitol & + & - & - & - \\
$N$-Acetylglucosamine & - & + & - & - \\
Amygdalin & + & - & - & - \\
Arbutin & + & - & - & - \\
Aesculin & + & - & - & - \\
Salicin & + & - & - & - \\
Cellobiose & + & - & - & - \\
Lactose & + & - & + & + \\
D-Melibiose & - & - & + & + \\
Trehalose & + & - & + & + \\
$\beta$-Gentiobiose & + & - & - & - \\
L-Fucose & + & - & + & - \\
D-Arabitol & + & + & + \\
Gluconate & + & & - & + \\
5-Ketogluconate & + & & & \\
\hline
\end{tabular}

${ }^{*} \mathrm{~F}$, Fermentative; O, oxidative.

$\uparrow$ TMPD, Tetramethyl-p-phenylenediamine.

the Voges-Proskauer test, gelatin hydrolysis and gas production from glucose (Table 3 ).

Strain $130 \mathrm{Z}^{\mathrm{T}}$ produced acid from L-arabinose, Dribose, D-xylose, galactose, D-glucose, D-fructose, Dmannose, D-mannitol, D-sorbitol, amygdalin, arbutin, aesculin, salicin, cellobiose, maltose, lactose, sucrose, raffinose, $\beta$-gentiobiose, D-arabitol, gluconate and 5- 
Table 4. Enzyme profiles produced by strain $130 Z^{\top}, A$. lignieresii, Bisgaard Taxon 6 and Bisgaard Taxon 10 as determined by the API ZYM system

1 , A. succinogenes sp. nov. ATCC $55618^{\mathrm{T}} ; 2$, A. lignieresii ATCC 49236; 3, Bisgaard Taxon 6 CCUG 15568; and 4, Bisgaard Taxon 10 CCUG 15572. All strains were positive for esterase (C4), esterase-lipase (C8), leucine arylamidase and $\beta$-galactosidase, but negative for lipase $(\mathrm{C} 14)$, valine arylamidase, cystine arylamidase, trypsin, chymotrypsin, $\beta$ glucuronidase, $N$-acetyl- $\beta$-glucosaminidase, $\alpha$-mannosidase and $\alpha$-fucosidase.

\begin{tabular}{|lcccc|}
\hline Enzyme activity & $\mathbf{1}$ & $\mathbf{2}$ & $\mathbf{3}$ & $\mathbf{4}$ \\
\hline Phosphohydrolase & + & - & + & + \\
$\alpha$-Galactosidase* & - & - & + & + \\
$\alpha$-Glucosidase & - & - & + & - \\
$\beta$-Glucosidase & + & - & - & - \\
Acid phosphatase, alkaline & + & $++\dagger$ & + & + \\
phosphatase & & & & \\
\hline
\end{tabular}

* $\alpha$-Galactosidase activity was determined by the RapID ANA II System.

$\dagger$ Strong positive reaction.

ketogluconate (Table 3). It produced no change with glycerol, erythritol, D-arabinose, L-xylose, adonitol, methyl $\beta$-xyloside, L-sorbose, L-rhamnose, dulcitol, inositol, methyl $\alpha$-D-mannoside, methyl $\alpha$-D-glucoside, $\mathrm{N}$-acetylglucosamine, D-melibiose, trehalose, inulin, melezitose, amidon, glycogen, xylitol, D-turanose, Dlyxose, D-tagatose, D-fucose, L-fucose, L-arabitol or 2ketogluconate (Table 3). Tests were not examined beyond $48 \mathrm{~h}$ so some additional late reactions could be possible.

In the API ZYM analysis, strain $130 \mathrm{Z}^{\mathrm{T}}$ produced positive reactions for alkaline phosphatase, esterase (C4), esterase-lipase (C8), leucine arylamidase, phosphohydrolase, $\beta$-galactosidase and $\beta$-glucosidase, and it gave a weak reaction for acid phosphatase. There was no reaction for lipase (C14), valine arylamidase, cystine arylamidase, trypsin, chymotrypsin, $\alpha$-galactosidase, $\beta$-glucuronidase, $\alpha$-glucosidase, $N$-acetyl- $\beta$-glucosaminidase, $\alpha$-mannosidase and $\alpha$-fucosidase (Table 4).

The RapID ANA II system confirmed the presence of $\beta$-glucosidase and $\beta$-galactosidase activities, and the lack of tryptophanase (indole), urease, $N$-acetyl $\beta$ glucosaminidase, $\alpha$-fucosidase and $\alpha$-glucosidase activities. The RapID ANA II system detected four additional activities: arginine arylamidase (strong positive), leucyl-glycine arylamidase, phenylalanine arylamidase and serine arylamidase. A positive $\beta$ glucosidase activity was consistent with acid from cellobiose, salicin and the other $\beta$-glucosides (Table 3 ). $\beta$-Disaccharidase, arabinosidase, $\alpha$-galactosidase, leucine, glycine, proline, phenylalanine, serine and pyroglutamic acid arylamidases were absent, as determined by the RapID ANA II system.
Table 5. Methylated cellular components of cells grown aerobically for $48 \mathrm{~h}$ on TSB agar plates

1, A. succinogenes sp. nov. ATCC $55618^{\mathrm{T}} ; 2$, A. lignieresii ATCC 49236; 3, Bisgaard Taxon 6 CCUG 15568; and 4, Bisgaard Taxon 10 CCUG 15572.

\begin{tabular}{|lrrrr|}
\hline Component FAME & \multicolumn{4}{c|}{$\begin{array}{c}\text { Total chromatographic area } \\
\text { (\%) }\end{array}$} \\
\cline { 2 - 6 } & \multicolumn{1}{c}{$\mathbf{1}$} & \multicolumn{2}{c|}{$\mathbf{2}$} & \multicolumn{3}{c|}{$\mathbf{3}$} & $\mathbf{4}$ \\
\hline $\mathrm{C}_{12: 0}$ & $0 \cdot 0$ & $0 \cdot 0$ & $1 \cdot 7$ & $2 \cdot 4$ \\
$\mathrm{C}_{16: 1}$ cis 9 & $34 \cdot 1$ & $32 \cdot 7$ & $36 \cdot 8$ & $36 \cdot 1$ \\
$\mathrm{C}_{14: 0}$ & $26 \cdot 0$ & $30 \cdot 8$ & $18 \cdot 7$ & $20 \cdot 4$ \\
$\mathrm{C}_{16: 0}$ & $20 \cdot 1$ & $16 \cdot 0$ & $24 \cdot 4$ & $23 \cdot 8$ \\
$\mathrm{C}_{14: 0}$ 3-OH or $\mathrm{C}_{16: 1}$ iso & $16 \cdot 4$ & $17 \cdot 5$ & $13 \cdot 3$ & $13 \cdot 2$ \\
$\mathrm{C}_{18: 1}$ cis $11 / t 9 / t 6$ or & $1 \cdot 3$ & $0 \cdot 0$ & $1 \cdot 7$ & $2 \cdot 0$ \\
$\mathrm{C}_{18: 1}$ trans $9 / t 6 / c 11$ or & & & & \\
$\mathrm{C}_{18: 1}$ trans $6 / t 9 / \mathrm{c} 11$ & & & & \\
\hline
\end{tabular}

\section{Fumarate respiration}

Strain $130 Z^{\mathrm{T}}$ had increased turbidity as a result of fumarate respiration. The turbidity increased by approximately $1 \mathrm{OD}$ unit in a medium containing sodium fumarate but lacking carbohydrate. Tubes lacking sodium fumarate did not show any increase in turbidity. Fumarate is used as a terminal electron acceptor in dimethylmenaquinone-mediated anaerobic respiration which is a characteristic of bacteria within the family Pasteurellaceae (Hollander et al., 1981). The response to fumarate was determined simultaneously for strain $130 Z^{\mathrm{T}}$ and the three reference strains. Strain $130 \mathrm{Z}^{\mathrm{T}}$ and Bisgaard Taxon 10 produced approximately 1.0 OD units from fumarate respiration in $15 \mathrm{~h}$, while Bisgaard Taxon 6 produced approximately $0.75 \mathrm{OD}$ units from fumarate. $A$. lignieresii turbidity increased 0.45 OD units with added fumarate.

\section{Cellular fatty acids}

The major fatty acid derivatives of strain $130 \mathrm{Z}^{\mathrm{T}}$ and $A$. lignieresii were $\mathrm{C}_{14: 0}, \mathrm{C}_{16: 0}$ and $\mathrm{C}_{16: 1}$ cis 9 FAME. A fourth major component was either $\mathrm{C}_{14: 0} 3-\mathrm{OH}$ FAME, $\mathrm{C}_{16: 1}$ iso FAME, or a combination of the two esters. These esters were not separated sufficiently to be reported as individual components, but are reported as a combined feature by the MIDI Microbial Identification System. Strain $130 \mathrm{Z}^{\mathrm{T}}$ and the Bisgaard Taxa 6 and 10 produced a minor amount of either $C_{18: 1}$ cis or $\mathrm{C}_{18: 1}$ trans FAMEs. The Bisgaard Taxa also produced a minor amount of $\mathrm{C}_{12: 0}$. Cellular fatty acid data for both species are shown in Table 5. The results were consistent with reports that members of the family Pasteurellaceae produce a restricted profile of fatty acids with major amounts of hexadecanoate $\left(\mathrm{C}_{16: 1}\right)$, ntetradecanoate $\left(\mathrm{C}_{14: 0}\right)$, 3-hydroxy-tetradecanoate $\left(\mathrm{C}_{14: 0} 3-\mathrm{OH}\right)$ and $n$-hexadecanoate $\left(\mathrm{C}_{16: 0}\right)$, and minor amounts of octadecenoate $\left(\mathrm{C}_{18: 1}\right)$ (Jantzen et al., 1981). 


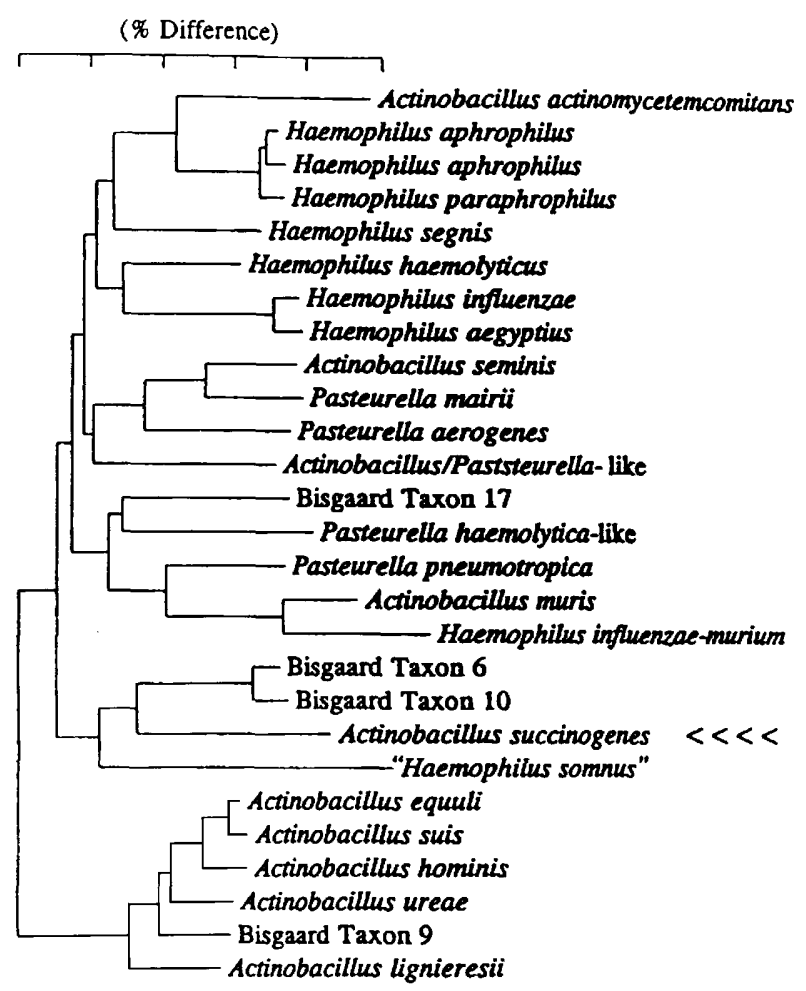

Fig. 2. Dendrogram of $16 \mathrm{~S}$ rRNA relationship of strain $130 Z^{\top}$ to members of the family Pasteurellaceae. It was generated from the similarity data using the neighbour-joining method of Saitou \& Nei (1987).

\section{DNA G + C base composition}

The DNA obtained from strain $130 Z^{\mathrm{T}}$ had a $\mathrm{G}+\mathrm{C}$ base content of $45.1 \mathrm{~mol} \%$, as determined by HPLC (Mesbah et al., 1989). The DNA from Bisgaard Taxon 6 was reported to have a $G+C$ content of $51.2 \mathrm{~mol} \%$ (Bisgaard et al., 1983). Although these were substantially different, the DNA $\mathrm{G}+\mathrm{C}$ base compositions of actinobacilli are quite variable and are reported not to be useful for differentiating species of actinobacilli (Phillips, 1992).

\section{Phylogenetic affiliation and 16S rRNA sequence analysis}

The essentially complete 16S rRNA sequence (1441 bases) was determined for strain $130 \mathrm{Z}^{\mathrm{T}}$. Sequence comparison with organisms in the database indicated that strain $130 \mathrm{Z}^{\mathrm{T}}$ was clearly a member of the family Pasteurellaceae. The sequence for strain $130 \mathrm{Z}^{\mathrm{T}}$ was compared to 26 previously sequenced members of the Pasteurellaceae (Table 2) and a similarity matrix based upon comparisons at 1423 base positions was produced. Table 2 shows levels of $16 \mathrm{~S}$ rRNA similarity between strain $130 \mathrm{Z}^{\mathrm{T}}$ (Actinobacillus succinogenes $\mathrm{sp}$. nov.) and other representatives of the family Pasteurellaceae. A phylogenetic tree was generated from the similarity data by the neighbour-joining method (Fig. 2). Strain $130 \mathrm{Z}^{\mathrm{T}}$ is most closely related to strains representing Bisgaard Taxon $6(4 \cdot 7 \%$ difference), Bisgaard Taxon $10 \quad(4.8 \%$ difference $)$ and 'Haemophilus somnus' (6.7\% difference). These organisms correspond to cluster $2 \mathrm{~B}$ in the previously published phylogenetic description of the Pasteurellaceae (Dewhirst et al., 1993).

Of the organisms within cluster $2 \mathrm{~B}$, ' $H$. somnus' had the lowest level of sequence similarity with strain $130 \mathrm{Z}$. ' $H$. somnus' and strain $130 \mathrm{Z}^{\mathrm{T}}$ were also phenotypically dissimilar. ' $H$. somnus' is a fastidious Gram-negative rod that occurs commensally in normal cattle but also causes disease; it has been studied rather extensively (Kirkham et al., 1989; Stephens et al., 1983; Ward et al., 1995). All ' $H$. somnus' strains were fastidious in their growth requirements and grew well only in media containing blood or tissue extracts. Growth was stimulated by TMP or by cross feeding with $S$. aureus. It did not grow in air but required $10 \%(\mathrm{v} / \mathrm{v}) \mathrm{CO}_{2}$ for growth. Stephens et al. (1983) found that most strains did not grow on sugars other than glucose.

' $H$. somnus' differed from strain $130 \mathrm{Z}^{\mathrm{T}}$ by its fastidious growth requirements, inability to grow in air, and by the production of $\beta$-glucuronidase and tryptophanase (indole). Unlike strain $130 \mathrm{Z}^{\mathrm{T}}$, ' $H$. somnus' lacked catalase, $\beta$-galactosidase and $\beta$-glucosidase activities, and it did not hydrolyse aesculin or produce acid from L-arabinose, cellobiose, lactose, maltose, raffinose, salicin or sucrose. Unlike ' $H$. somnus', strain $130 \mathrm{Z}^{\mathrm{T}}$ was not stimulated by TMP or cross-fed by $S$. aureus.

The other taxa within cluster $2 \mathrm{~B}$ were the Bisgaard Taxa 6 and 10 which had a low level of $16 \mathrm{~S}$ rRNA sequence similarity $(\cong 95.5 \%)$ with strain $130 \mathrm{Z}^{\mathrm{T}}$ and numerous phenotypic distinctions. Strain $130 Z^{T}$ was catalase-, oxidase- and $\beta$-glucosidase-positive, ureasenegative and non-aerogenic; strain $130 \mathrm{Z}^{\mathrm{T}}$ could be distinguished from either Bisgaard Taxon 6 or Bisgaard Taxon 10 by any of these characteristics.

The Bisgaard Taxon 6 strain was originally isolated from two different colonies of healthy guinea pigs and it made up to $50 \%$ of the guinea pig pharyngeal flora (Bisgaard et al., 1983). Lower portions of the alimentary tract were not investigated. It was isolated on blood-containing agar but it grew on TSB agar plates in a similar fashion to strain $130 Z^{T}$. Notably, seven strains isolated from guinea pigs and wild muskrat have been classified as Actinobacillus species (Boot \& Bisgaard, 1994). Bisgaard Taxon 10 is also nonfastidious and can be cultured on TSB agar. It was isolated from the equine oral cavity but no publications were found regarding the circumstances surrounding its isolation. The horse's mouth is replete with indigenous members of the family Pasteurellaceae (Samitz \& Biberstein, 1991). Both of the Bisgaard taxa could be grown aerobically or in high concentrations of $\mathrm{CO}_{2}$.

Bisgaard Taxon 6 differed from strain $130 \mathrm{Z}^{\mathrm{T}}$ by the presence of urease, $\alpha$-galactosidase and $\alpha$-glucosidase activities, the production of gas from glucose, and the 
lack of $\beta$-glucosidase activity. Major differences regarding the substrates fermented by Bisgaard Taxon 6 and strain $130 \mathrm{Z}^{\mathrm{T}}$ were observed (Table 3 ). Bisgaard Taxon 6 failed to ferment amygdalin, gentiobiose, arbutin, aesculin, salicin, cellobiose, mannitol, sorbitol or D-arabitol. Bisgaard Taxon 6 type strain produced acid from $\mathrm{D}$-arabinose, and produced acid and gas from L-fucose. Trehalose and melibiose were fermented, which is consistent with the presence of $\alpha-$ galactosidase (Tables 3 and 4). Bisgaard Taxon 6 produced gas from a number of substrates other than glucose and L-fucose, including fructose, mannose, maltose, lactose, sucrose, trehalose, gluconate and 5ketogluconate. Bisgaard Taxon 6 and strain 130Z were biochemically distinct species.

Bisgaard Taxon 10 differed from strain $130 \mathrm{Z}^{\mathrm{T}}$ by the presence of urease and $\alpha$-galactosidase activities, the production of gas from glucose, and the lack of $\beta$ glucosidase activity. There were major differences regarding the substrates fermented by Bisgaard Taxon 10 and strain $130 Z^{\mathrm{T}}$ (Table 3). Bisgaard Taxon 10 failed to ferment amygdalin, gentiobiose, arbutin, aesculin, salicin, cellobiose, sorbitol, D-arabitol and Dxylose. Bisgaard Taxon 10 fermented D-arabinose and rhamnose. Fermentation of trehalose and melibiose were consistent with the presence of $\alpha$-galactosidase. Bisgaard Taxon 10 produced gas from a number of substrates other than glucose including fructose, mannose, mannitol, maltose, gluconate and 5-ketogluconate. Although both Bisgaard Taxa 6 and 10 shared some general growth characteristics with strain $130 \mathrm{Z}^{\mathrm{T}}$, they were phenotypically distinct from strain $130 \mathrm{Z}^{\mathrm{T}}$ based on numerous biochemical differences (Table 3). Strain $130 Z^{T}$ was also phylogenetically distinct from both Taxon 6 and Taxon 10 based on the differences in their 16S rRNA sequences (4.7 and $4.8 \%$, respectively). Strain $130 \mathrm{Z}^{\mathrm{T}}$ and Bisgaard Taxa DNA-DNA hybridizations were not done because 16S rRNA similarities were less than $96 \%$ and DNA-DNA reassociation values were expected to be low. Strains of the same species have at least $60-70 \%$ DNA similarity. Therefore, the DNA-DNA reassociation studies become particularly useful when 16S rRNA similarities are $97 \%$ or higher (Stackebrandt, 1994).

Of the accepted species of Actinobacillus, Actinobacillus capsulatus shared many biochemical properties of strain $130 \mathrm{Z}^{\mathrm{T}}$. Samitz \& Biberstein (1991) used the same API batteries of reactions to biotype wild isolates and reference strains including $A$. capsulatus. The reactions of the $A$. capsulatus reference strain were similar to those of strain $130 \mathrm{Z}^{\mathrm{T}}$, except that $130 \mathrm{Z}^{\mathrm{T}} \mathrm{did}$ not produce acid from melibiose, trehalose or $N$ acetylglucosamine. Unlike $A$. capsulatus, strain $130 \mathrm{Z}^{\mathrm{T}}$ did not produce $\alpha$-galactosidase or $\alpha$-glucosidase but did produce $\beta$-glucosidase. Strain $130 \mathrm{Z}^{\mathrm{T}}$ lacked the capsule present in A. capsulatus. According to Samitz $\&$ Biberstein (1991), the capsule is so pronounced that $A$. capsulatus cells are difficult to sediment by centrifugation. Strain $130 \mathrm{Z}^{\mathrm{T}}$ produces an extracellular slime under certain conditions, which is typical of members of the genus Actinobacillus (Phillips, 1984), but strain $130 \mathrm{Z}^{\mathrm{T}}$ is not known to form a compact capsule under any experimental conditions. Based upon $16 \mathrm{~S}$ sequence information, strain $130 \mathrm{Z}^{\mathrm{T}}$ lies within cluster $2 \mathrm{~B}$, while A. capsulatus lies within cluster $3 \mathrm{C}$ at a considerable phylogenetic distance from strain $130 \mathrm{Z}^{\mathrm{T}}$ (Dewhirst et al., 1993).

Based upon phylogenetic placement, phenotypic properties and the ability to produce succinic acid, it is proposed that strain $130 \mathrm{Z}^{\mathrm{T}}$ be included in the genus Actinobacillus as the type strain of a new species, Actinobacillus succinogenes. Strain $130 \mathrm{Z}^{\mathrm{T}}$ is phenotypically most similar to the genus Actinobacillus. Placement within the genus Actinobacillus will also serve to call attention to its source in the bovine rumen. Phillips (1961) proposed that there were 'rumen actinobacilli' that had an enhanced fermentative activity and that were typically catalase-positive and urease-negative. It is recognized in this study that there is a new body of knowledge concerning the family Pasteurellaceae that is being built from 16S rRNA sequence determinations and that the structure of the family Pasteurellaceae will be changed in the future based upon 16S rRNA information and other molecular approaches. It is also recognized that strains within the 2B subcluster of Pasteurellaceae may not fit with any Pasteurella, Haemophilus, or Actinobacillus sensu stricto genus definitions (Dewhirst et al., 1993), and that the genus designation for Actinobacillus succinogenes may be changed in the future.

\section{Description of Actinobacillus succinogenes sp. nov.}

Actinobacillus succinogenes (suc.ci.no'ge.nes. M.L. n. acidum succinicum succinic acid; Gr. v. gennaio to produce; M.L. adj. succinogenes succinic-acid-producing).

Cells are non-motile, pleomorphic, Gram-negative rods $(0.8 \times 1 \mu \mathrm{m})$. Occasional filamentous cells are seen in most cultures. 'Morse code' forms and chains are common in actively growing broth cultures. Cells within an extracellular matrix are common in aerobically grown cultures. Chemo-organotrophic. Yeast extract and $\mathrm{CO}_{2}$ stimulate growth. Colonies produced on TSB agar are circular, entire, grey, translucent and $1-1.5 \mathrm{~mm}$ in diameter after $24 \mathrm{~h}$ incubation at $37^{\circ} \mathrm{C}$ with $\mathrm{CO}_{2}$. Growth occurs at $37-39^{\circ} \mathrm{C}$, but not at 20 or $45^{\circ} \mathrm{C}$. Catalase- and oxidase-positive. Alkaline phosphatase-positive. Acid but no gas is produced within $24 \mathrm{~h}$ from D-glucose and D-fructose. Acid is also produced with L-arabinose, D-ribose, D-xylose, galactose, D-mannose, D-mannitol, D-sorbitol, amygdalin, arbutin, aesculin, salicin, cellobiose, maltose, lactose, sucrose, raffinose, $\beta$-gentiobiose, D-arabitol, gluconate or 5-ketogluconate. Acid is not produced from dulcitol, inositol, inulin, glycerol, erythritol, Darabinose, L-xylose, adonitol, methyl $\beta$-xyloside, Lsorbose, L-rhamnose, methyl $\alpha$-D-mannoside, methyl 
$\alpha$-D-glucoside, $N$-acetylglucosamine, D-melibiose, trehalose, melezitose, amidon, glycogen, xylitol, D-turanose, D-lyxose, D-tagatose, D-fucose, L-fucose, Larabitol and 2-ketogluconate. $\beta$-Galactosidase, arginine- $\beta$-arylamidase and leucine arylamidase were produced in large amounts. Nitrates are reduced to nitrites. Indole and urease are not produced. Rapid and extensive growth observed utilizing arabinose, cellobiose, fructose, galactose, glucose, lactose, maltose, mannitol, mannose, sucrose, xylose or salicin in media made with yeast extract and CSL. Marked production of succinic acid in the presence of $\mathrm{CO}_{2}$ and high substrate concentration. DNA G $+\mathrm{C}$ content is approximately $45 \mathrm{~mol} \%$. The type strain, strain $130 \mathrm{Z}^{\mathrm{T}}$, was isolated from the bovine rumen, preserved by freezing in glycerol vials and by lyophilization, and has been deposited in the American Type Culture Collection as ATCC $55618^{\mathrm{T}}$.

\section{Occurrence and role of Actinobacillus succinogenes sp. nov. in the rumen}

Actinobacillus succinogenes was isolated from ruminal contents. It is a capnophilic, osmotolerant and highly productive saccharolytic succinogen utilizing a broad range of sugars. These general properties are suggestive of a micro-organism that is adapted to a symbiotic role in the rumen. The present description of $A$. succinogenes may lead to additional isolations of this organism and information regarding its frequency of occurrence in the bovine rumen or possibly other ruminants.

A. succinogenes is an acidogenic strain that has a conspicuous ability to accumulate very high concentrations of succinic acid. Strain $130 \mathrm{Z}^{\mathrm{T}}$ initiated growth in the presence of high glucose concentrations, and produced $74 \mathrm{~g}$ succinic acid $\mathrm{l}^{-1}$ in vials that contained increased amounts of glucose and $\mathrm{MgCO}_{3}$. Some derivatives of strain $130 \mathrm{Z}^{\mathrm{T}}$ accumulated more than $100 \mathrm{~g}$ succinic acid $\mathrm{l}^{-1}$ in vials containing yeast extract/CSL medium (Guettler et al., 1996a, b).

\section{ACKNOWLEDGEMENTS}

This work was supported in part by a grant (\#94-341890067) from the US Department of Agriculture. We thank Dr Floyd E. Dewhirst (Forsyth Dental Center, Boston, MA, USA) for his technical assistance, insight and advice regarding the $16 \mathrm{~S}$ rRNA sequence analysis and phylogenetic determination of strain 130Z. We are grateful to Dr William B. Whitman (University of Georgia, Athens, GA, USA) for performing the $\mathrm{G}+\mathrm{C}$ determination for us. We also thank Innovative Diagnostic Systems for supplying the RapID ANA II kits.

\section{REFERENCES}

Bisgaard, M., Mutters, R. \& Mannheim, W. (1983). Characterization of some previously unreported taxa isolated from guineapigs (Cavia porcellus) and provisionally classed with the 'HPA-group'. INSERM 114, 227-244.
Bisgaard, M., Phillips, J. E. \& Mannheim, W. (1986). Characterization and identification of bovine and ovine Pasteurellaceae isolated from the oral cavity and rumen of apparently normal cattle and sheep. Acta Pathol Microbiol Immunol Scand Sect B Microbiol 94, 9-17.

Boot, R. \& Bisgaard, M. (1994). Reclassification of 30 Pasteurellaceae strains isolated from rodents. Lab Anim 29, 314-319.

Dewhirst, F. E., Paster, B. J., Olsen, I. \& Fraser, G. J. (1993). Phylogeny of the Pasteurellaceae as determined by comparison of $16 \mathrm{~S}$ ribosomal ribonucleic acid sequences. Zentbl Bakteriol 279, 35-44.

Foster, G., Ross, H. M., Malnick, H., Willems, A. \& Garcia, P. (1996). Actinobacillus delphinicola sp. nov., a new member of the family Pasteurellaceae Pohl (1979) 1981 isolated from sea mammals. Int J Syst Bacteriol 46, 648-652.

Guerrant, G. O., Lambert, M. A. \& Moss, C. W. (1982). Analysis of short-chain acids from anaerobic bacteria by high-performance liquid chromatography. $J$ Clin Microbiol 16, 355-360.

Guettler, M. V., Jain, M. K. \& Soni, B. K. (1996a). Process for making succinic acid, microorganisms for use in the process and methods of obtaining the microorganisms. US Patent 5504004.

Guettler, M. V., Jain, M. K. \& Rumler, D. (1996b). Method for making succinic acid, bacterial variants for use in the process, and methods for obtaining the variants. US Patent 5573931.

Holdeman, L. V., Cato, E. P. \& Moore, W. E. C. (1977). Anaerobe Laboratory Manual, 4th edn. Blacksburg, VA: Virginia Polytechnic Institute and State University.

Hollander, R., Hess-Reihse, A. \& Mannheim, W. (1981). Respiratory quinones in Haemophilus, Pasteurella and Actinobacillus: pattern, function, and taxonomic evaluation. In Haemophilus, Pasteurella and Actinobacillus, pp. 92-93. Edited by M. Kilian, W. Frederiksen \& E. L. Biberstein. London: Academic Press.

Jantzen, E., Berdal, B. P. \& Omland, T. (1981). Cellular and fatty acid taxonomy of Haemophilus, Pasteurella, and Actinobacillus. In Haemophilus, Pasteurella and Actinobacillus, pp. 197-203. Edited by M. Kilian, W. Frederiksen \& E. L. Biberstein. London: Academic Press.

Jukes, T. H. \& Cantor, C. R. (1969). Evolution of protein molecules. In Mammalian Protein Metabolism, vol. 3, pp. 21-132. Edited by H. N. Munro. New York: Academic Press.

Kilian, M. \& Biberstein, E. L. (1984). Genus II Haemophilus. In Bergey's Manual of Systematic Bacteriology, vol. 1, pp. 561-562. Edited by N. R. Krieg \& J. G. Holt. Baltimore: Williams \& Wilkins.

Kirkham, C., Biberstein, E. L. \& LeFebvre, R. B. (1989). Evidence of host-specific subgroups among 'Histophilus ovis' isolates. Int $J$ Syst Bacteriol 39, 236-239.

Kusukawa, N., Uemori, T., Asada, K. \& Kato, I. (1990). Rapid and reliable protocol for direct sequencing of material amplified by the polymerase chain reaction. Biotechniques 9, 66-72.

MacFaddin, J. F. (1980). Biochemical Tests for Identification of Medical Bacteria, 2nd edn. Baltimore: Williams \& Wilkins.

Macy, J. M., Snellen, J. E. \& Hungate, R. E. (1972). Use of syringe methods for anaerobiosis. J Clin Nutr 25, 1318-1323.

Maidak, B. L., Olsen, G. J., Larsen, N., Overbeek, R., McCaughey, M. J. \& Woese, C. R. (1997). The RDP (Ribosomal Database Project). Nucleic Acids Res 25, 109-111.

Mannheim, W. (1984). Family III Pasteurellaceae Pohl 1981a, 382. In Bergey's Manual of Systematic Bacteriology, vol. 1, pp. 550-552. Edited by N. R. Krieg \& J. G. Holt. Baltimore: Williams \& Wilkins. 
Mendes, E. N., Queiroz, D. M. M., Dewhirst, F. E., Paster, B. J., Moura, S. B. \& Fox, J. G. (1996). Helicobacter trogontum sp. nov., isolated from the rat intestine. Int J Syst Bacteriol 46, 916-921.

Mesbah, M., Premachandran, U. \& Whitman, W. B. (1989). Precise measurement of the $\mathrm{G}+\mathrm{C}$ content of deoxyribonucleic acid by high-performance liquid chromatography. Int $J$ Syst Bacteriol 39, 159-167.

Miller, T. L. \& Wolin, M. J. (1974). A serum bottle modification of the Hungate technique for cultivating obligate anaerobes. Appl Microbiol 27, 985-987.

Osawa, R., Rainey, F., Fujisawa, T., Lang, E., Busse, H. J., Walsh, T. P. \& Stackebrandt, E. (1995). Lonepinella koalarum gen. nov., a new tannin-protein complex degrading bacterium. Syst Appl Microbiol 18, 368-373.

Paster, B. J. \& Dewhirst, F. E. (1988). Phylogeny of campylobacters, wolinellas, Bacteroides gracilis, and Bacteroides ureolyticus by $16 \mathrm{~S}$ ribosomal ribonucleic acid sequencing. Int $J$ Syst Bacteriol 38, 56-62.

Phillips, J. E. (1961). The commensal role of Actinobacillus lignieresii. J Path Bacteriol 82, 205-208.

Phillips, J. E. (1984). Genus III Actinobacillus Brumpt 1910, $849^{\mathrm{AL}}$. In Bergey's Manual of Systematic Bacteriology, vol. 1, pp. 570-575. Edited by N. R. Krieg \& J. G. Holt. Baltimore: Williams \& Wilkins.

Phillips, J. E. (1992). The genus Actinobacillus. In The Prokaryotes, a Handbook on the Biology of Bacteria: Ecophysiology, Isolation, Identification, Applications, 2nd edn, vol. IV, pp. 3342-3351. Edited by A. Balows, H. G. Trüper, M. Dworkin, W. Harder \& K.-H. Schleifer. New York: Springer.

Saitou, N. \& Nei, M. (1987). The neighbor-joining method: a new method for reconstructing phylogenetic trees. Mol Biol Evol 4, $406-425$.

Samitz, E. M. \& Biberstein, E. L. (1991). Actinobacillus suis-like organisms and evidence of hemolytic strains of Actinobacillus lignieresii in horses. Am J Vet Res 52, 1245-1251.

Sasser, M. (1990). Identification of bacteria by gas chromatography of cellular fatty acids. Technical Note 101. Newark, DE: MIDI.

Stackebrandt, E. \& Goebel, B. M. (1994). Taxonomic note: a place for DNA-DNA reassociation and 16S rRNA sequence analysis in the present species definition in bacteriology. Int $J$ Syst Bacteriol 44, 846-849.

Stephens, L. R., Humphrey, J. D., Little, P. B. \& Barnum, D. A. (1983). Morphological, biochemical, antigenic, and cytochemical relationships among Haemophilus somnus, Haemophilus agni, Haemophilus haemoglobinophilus, Histophilus ovis, and Actinobacillus seminis. J Clin Microbiol 17, 728-737.

Stewart, C. S. \& Bryant, M. P. (1988). The rumen bacteria. In The Rumen Microbial Ecosystem, pp. 21-75. Edited by P. N. Hobson. London: Elsevier.

Studier, J. \& Keppler, K. (1988). A note on the neighbor-joining algorithm of Saitou and Nei. Mol Biol Evol 5, 729-731.

Van der Werf, M. J., Guettler, M. V., Jain, M. K. \& Zeikus, J. G. (1997). Environmental and physiological factors affecting the succinate product ratio during carbohydrate fermentation by Actinobacillus sp. 130Z. Arch Microbiol 167, 332-342.

Ward, A. C. S., Jaworski, M. D., Eddow, J. M. \& Corbeil, L. B. (1995). A comparative study of bovine and ovine Haemophilus somnus isolates. Can J Vet Res 59, 173-178.

Yokoyama, M. T. \& Johnson, K. A. (1988). Microbiology of the rumen and intestine. In The Ruminant Animal: Digestive Physiology and Nutrition, pp. 125-144. Edited by D. C. Church. NJ: Prentice Hall.

Zeikus, J. G., Ben-Bassat, A. \& Hegge, P. W. (1980). Microbiology of methanogenesis in thermal volcanic environments. $J$ Bacteriol 143, 432-464. 